\title{
Development of Linear Generator System Combined with Magnetic Damping Function
}

\author{
Yasuaki SAKAMOTO
}

Administration Division

\author{
Erimitsu SUZUKI \\ Administration Division
}

\author{
Takayuki KASHIWAGI \\ Electromagnetic Applications Laboratory, \\ Maglev Systems Technology Division \\ Katsuya YAMAMOTO \\ Vehicle Noise \& Vibration Laboratory, \\ Vehicle Structure Technology Division
}

\author{
Toshiaki MURAI \\ Central Japan Railway Company
}

\begin{abstract}
One of the most important subjects in the superconducting Maglev system is a method for providing onboard service power. As a solution, a linear generator is being developed that can collect power without contact by utilizing the harmonic magnetic field around the ground coils and generate an electromagnetic force between them and the superconducting magnets by controlling the current in the generator coils. By using this controllable electromagnetic force, it becomes possible to add magnetic damping to the electrodynamic levitation system with a small damping force. This paper describes the results of the running tests of the linear generator using zero-phase current control, combined with the magnetic damping function.
\end{abstract}

Keywords: Superconducting Maglev, magnetic damping, zero-phase current

\section{Introduction}

The superconducting Maglev system's high speed and levitation method of operation make a noncontact power collection system desirable in the case of power collection from the ground for an onboard power source, and a lightweight and clean power source in the case of onboard generation or battery supply.

On the other hand, for electrodynamic suspension between the ground and bogie (called the primary suspension), its intrinsic damping is small or may theoretically be negative and many research studies ${ }^{1)}$ have been conducted into how to improve its damping characteristics. It is not realistic to install a new coil in the narrow air gap between the superconducting magnet and the ground coil only for damping purposes, so it has not been adopted on a real test vehicle, on which bogie vibration is small, because of the damper between the car body and the bogie (secondary suspension). But this damping effect cannot be gained at the primary suspension resonance frequency and so measurement to enable further improvements to the primary suspension is desired.

To meet the above needs, the authors have been developing a noncontact inductive power collection system ${ }^{2}$, which utilizes the harmonic magnetic field generated by induced current on the levitation coil. In addition to power collection, this system offers an extremely advantageous function in that an electromagnetic force can be added between the bogies and the ground by controlling the current flow on the generator collection coil. Because we can utilize this as a damping force by controlling the current, taking bogie movement into account, it is anticipated that a vibration control function can be added to the primary suspension, which doesn't have sufficient damping force, and thereby increase riding comfort ${ }^{3)}$. There are two ways of approaching current control combined with power collection. One is by controlling the power factor of the power collection circuit (called the reactive current method) and the other is by controlling its zero-phase current ${ }^{1}$ (the zero-phase current method ${ }^{4)}$ ). The latter can produce greater electromagnetic force, but there are many aspects of its development that need to be addressed, such as the shape and arrangement of the power collection coil ${ }^{5)}$, the converter control method, etc. We had performed experiments on a real test vehicle ${ }^{6)}$ and verified, for example, its basic power collection characteristics. This time, we tried the zero-phase current method on the real test vehicle and verified its power collection ability and the effect it had on bogie vibration suppression. In this paper, we describe the power collection system using the zerophase current method and report on the results of experiments carried out on the real test vehicle.

\footnotetext{
1 In ordinary balanced three phase current, sum of all phase ( $\mathrm{u}, \mathrm{v}$ and $\mathrm{w}$ ) currents is zero. "Zero-phase current" in this paper means sum of all phase currents in inductive power collection coils is not zero and rather we actively use this current component for damping force generation.
} 
2. Outline of power collection system using zero-phase current method

\subsection{Principle}

The system's basic configuration is shown in Fig. 1. In the superconducting Maglev system, the superconducting magnet (SCM) is used not only as a field coil for a linear synchronous motor but also as a magnetic pole for electrodynamic suspension (levitation and guidance) while running. With regard to the vertical suspension system (the levitation system), induced current flows through a figure-eight-shaped coil. As the levitation coils are arranged continuously in the direction of travel, the magnetic field generated by the levitation current with the same pitch (referred to as $\tau$ in this paper.) as the SCM pole reacts to the SCM and the vehicle levitates. Here the levitation coil has a concentrated winding, so the magnetic field caused by the levitation current is accompanied by harmonics. If the levitation coils have $\tau / 3$ pitch, the main harmonics have $\tau / 5$ pitch (5th space harmonics) and are 6 th time harmonics observed from onboard (about $309 \mathrm{~Hz}$ at a running speed of $500 \mathrm{~km} / \mathrm{h}$ ). If we arrange the figure-eight-shaped coil (the generator coil) on the surface of the SCM, the voltage is generated by this 5 th space and 6 th time harmonic magnetic field. By improving its power factor by DC conversion, we can obtain power.

The arrangement of the power collection coils is shown in Fig. 2: (a) shows the reactive current method, for which we arranged the coils at a regular harmonic pitch $(4 / 3 \tau)$, and (b) the zero-phase current method, where we arranged closed power collection coils in each SC coil and inversed their arrangement according to each SC coil's pole. Furthermore, U-phase and V-phase (W-phase) coils with different specifications were used to obtain an almost-balanced 3-phase induced voltage. Next, if we use singlephase and 3-phase pulse width modulation (PWM) converters and pass a current with the same phase through each coil, a magnetic field with the fundamental pitch $(\tau)$ is generated. This magnetic field induces current with the fundamental pitch in the levitation coils and a new electromagnetic force between the SCM and the levitation coils is originated. By controlling this electromagnetic force according to bogie vibration, vibration control can be achieved.

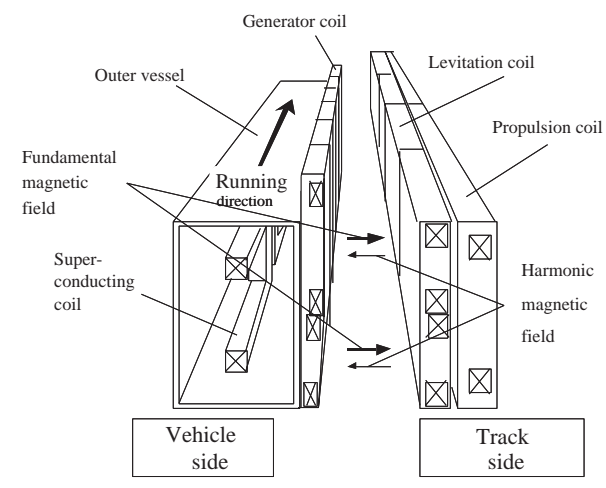

Fig. 1 Basic construction of linear generator

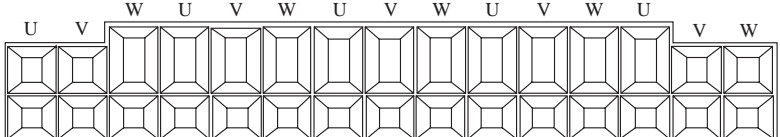

(a) Reactive current type

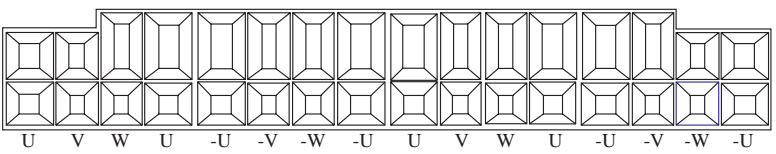

(b) Zero-phase current type

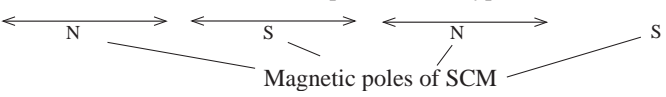

Fig. 2 Power collection coil arrangement

\subsection{Test equipment}

We show the zero-phase current-type linear generator system used for the real test run in Fig. 3, the main test equipment specifications in Table 1 and provide an overview of the generator coils mounted on the bogie set in Fig. 4. Although the generator coils were originally intended to be attached on both bogie sides, we arranged them on one side only for this test run. The generator coils and the PWM converter were connected using 3phase cables with six lines. Collected power converted from 3-phase AC power to DC power by instantaneous current control was supplied to onboard loads (SCM refrigerator, air conditioner, control unit power supply, service equipment, etc.). With due consideration given to the total power required for these onboard loads, we designed the test equipment with an output power of $25 \mathrm{~kW}$ (maximum $30 \mathrm{~kW}$ ). The main features of each piece of equipment are as follows.

(1) SCM: We reused the SCM that had been used in the previous test (for the reactive current-type linear generator). Some devices, such as an outer vessel reentrant corner, were incorporated to reduce the voltage drop induced by the shielding effect of the eddy current induced on the outer vessel and to suppress the increase in AC resistance of the power collection coils.

(2) Generator coils: Generator coils and their attachments must tolerate high electromagnetic forces from the high current density in the vicinity of the SCM as well as $500 \mathrm{~km} / \mathrm{h}$ wind pressure but must be as light as possible. By structural analysis, we optimized the

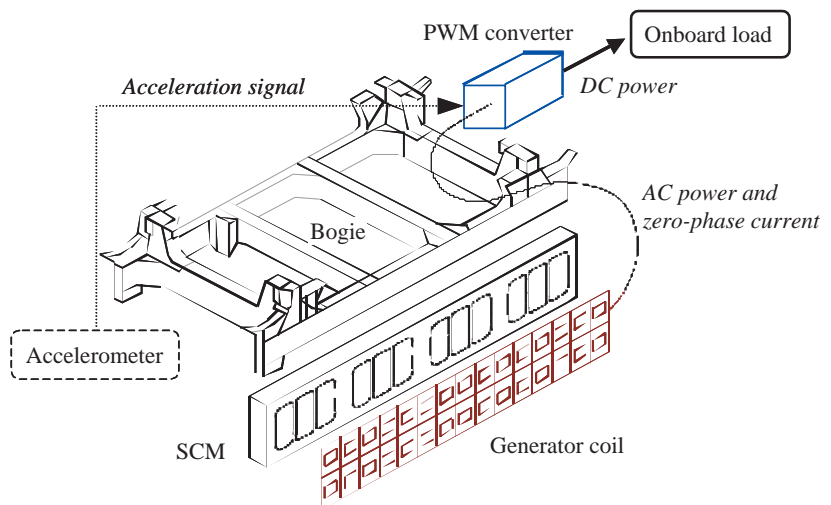

Fig. 3 Arrangement of test zero-phase current-type linear generator system 
Table 1 Test equipment specifications

\begin{tabular}{|c|c|}
\hline $\begin{array}{l}\text { Generator coil } \\
\text { dimensions - upper, lower }\end{array}$ & $\begin{array}{l}\mathrm{U}: \quad 240 \times 450 \mathrm{~mm}, 240 \times 260 \mathrm{~mm} \\
\mathrm{~V}, \mathrm{~W}: 220 \times 450 \mathrm{~mm}, 220 \times 260 \mathrm{~mm}\end{array}$ \\
\hline Number $\times$ turn & $\begin{array}{l}\mathrm{U}: \quad 8 \times 17 \\
\mathrm{~V}, \mathrm{~W}: 4 \times 26\end{array}$ \\
\hline $\begin{array}{l}\text { PWM converter } \\
\text { output }\end{array}$ & $30 \mathrm{~kW}(\max )$ \\
\hline DC voltage & $600 \mathrm{~V}$ \\
\hline Sampling frequency & $10 \mathrm{kHz}$ \\
\hline Efficiency & $90 \%$ \\
\hline
\end{tabular}

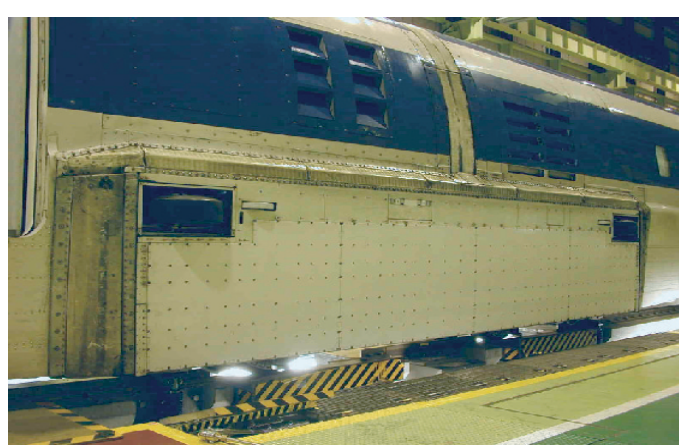

Fig. 4 Overview of generator coils mounted on bogie

shape of the fiber-reinforced plastic (FRP) coil panel and its bolt attachment arrangement.

(3) PWM converter: To enable the realization of some countermeasures simultaneously, such as the high power factor control of the generator coils' high reactance, zero-phase current control during vibration control and so on, we developed a new PWM converter that is capable of instantaneous power collection current control (power factor control) as well as zerophase current control.

(4) Damping control unit: In the case of vibration control, we needed equipment that could calculate in real time zero-phase current command values from bogie vibration. To this end, we developed damping control equipment that calculates the command value of zerophase current based on signals from vibration accelerometers mounted at several points on the bogies. For the sake of convenience, a basic control algorithm unit was also incorporated into the converter itself.

\subsection{Outline of control methods}

(1) Instantaneous current control: The equivalent circuit per one phase is shown in Fig. 5. The power collection circuit (AC side) has large reactance and a diode bridge rectifier circuit and so on are incapable of producing sufficient power. To improve the power factor, we developed an instantaneous current control method that utilizes a PWM converter. The basic schematic diagram (for u phase only) is shown in Fig. 6. $i_{u}$, $i_{v}$ and $i_{w}$ are measured power collection currents for the individual phase and from them we determined the voltage needed for power collection with a high power factor. We determined the output voltage of the PWM converter from basic instantaneous current control equations,

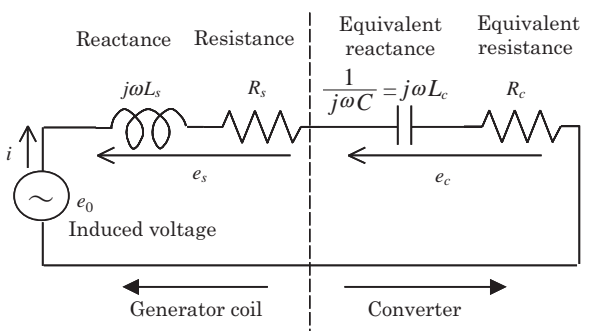

Fig. 5 Equivalent circuit of power collection system

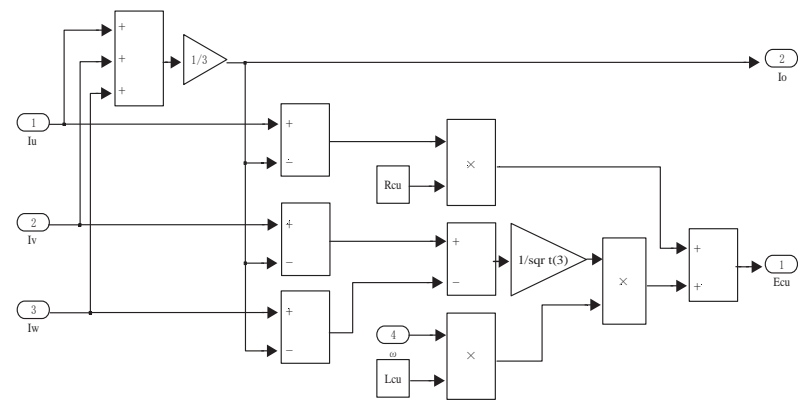

Fig. 6 Schematic explanation of instantaneous control (u phase)

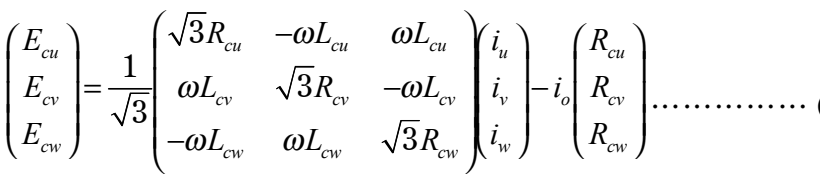

$$
\begin{aligned}
& i_{o}=\frac{1}{3}\left(i_{u}+i_{v}+i_{w}\right)
\end{aligned}
$$

Here, $E_{c i}, R_{c i}, L_{c i}, \omega(\mathrm{i}=\mathrm{u}, \mathrm{v}, \mathrm{w})$ are the command values of each phase converter voltage, equivalent converter resistance, equivalent converter reactance and angular frequency. Furthermore, to control collection power, a power control block which controls $R_{c i}$ by proportional-integral (PI) compensator was added.

(2) Zero-phase current control: Zero-phase current, which produces electromagnetic force, is controlled to follow the commanded value of $i_{c}{ }^{*}$ by PI control logic

A schematic voltage diagram for zero-phase current control is provided in Fig. 7.

The final converter voltage is determined by adding the two voltages calculated from the schematic diagrams in Fig. 6 and Fig. 7. As shown above, the power collection mode and zero-phase current control are independent so both can be controlled individually.

(3) Generated force control: For vibration control, several methods can be considered. We adopted a bang-bang control method, which generates electromagnetic force as a Coulomb friction force (the absolute value of force is constant and its sign is determined according to vibration velocity.). Concretely vertical bogie acceleration is integrated in the damping control equipment and vibration velocity calculated first, DC and any high-frequency components are eliminated through a band pass filter, before the maximum zero-phase current $I_{\max }$, which generates the damping force in the opposite direction to the bogie velocity is commanded. If we assign $v$ to the bogie velocity, the commanded 


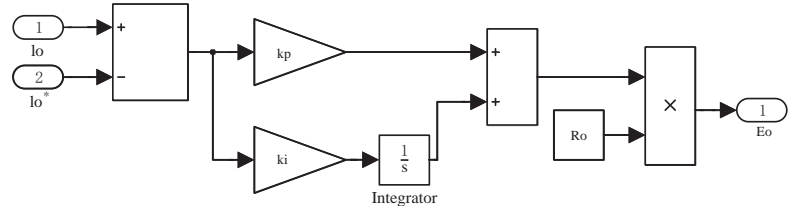

Fig. 7 Schematic explanation of voltage generation for zero-phase current control

zero-phase current $i_{0}{ }^{*}$ is given as follows.

$i_{o}^{*}=\left\{\begin{array}{l}I_{\max }(v<0) \\ -I_{\max }(v \geq 0)\end{array}\right.$

We input this into the schematic diagram shown in Fig. 7. Furthermore, we tested other control logic, for example, control using a force proportional to the friction force and control which limits frequency range and so on.

\section{Verification by real vehicle test}

\subsection{Outline of test}

After an on-site test that simulated magnetic field harmonics from a levitation coil using an inverter, we performed a test run as follows.

(1) Measurement of induced voltage: Under the condition that power collection circuits are opened on the PWM converter side, we measured the induced voltage of generator coils under various running conditions. We investigated the car body's aerodynamic lift force and the influence of the vehicle's location in the guideway (for example, induced voltage fluctuation is caused by lateral vibration of the car bogie).

(2) Power collection ability test: Under the condition that converter output is connected to the onboard power supply system, we confirmed the power collection characteristics and its stable operation under various running conditions.

(3) Vibration control test: We performed a vibration control test in which zero-phase current was added simultaneously to power collection current according to the vehicle vibration, under power collection mode conditions. We confirmed the vehicle and bogie dynamics characteristics under control and also confirmed power collection ability in this test.

\subsection{Test results}

\subsubsection{Induced voltage}

Figure 8 shows measured and calculated induced voltage under full load condition. For the induced voltage calculation, we used 3-dimensional FEM magnetic field analysis ${ }^{8)}$ and took into consideration the influence of eddy current's skin effect on the outer vessel and aerodynamic lift force on the vehicle. With respect to the absolute value of induced voltage, the average calculated and measured values on each phase coincided well with each other. There was a large amplitude unbalance on each phase from calculated values but, on the other hand, unbalance on the measured value was minimal (less than

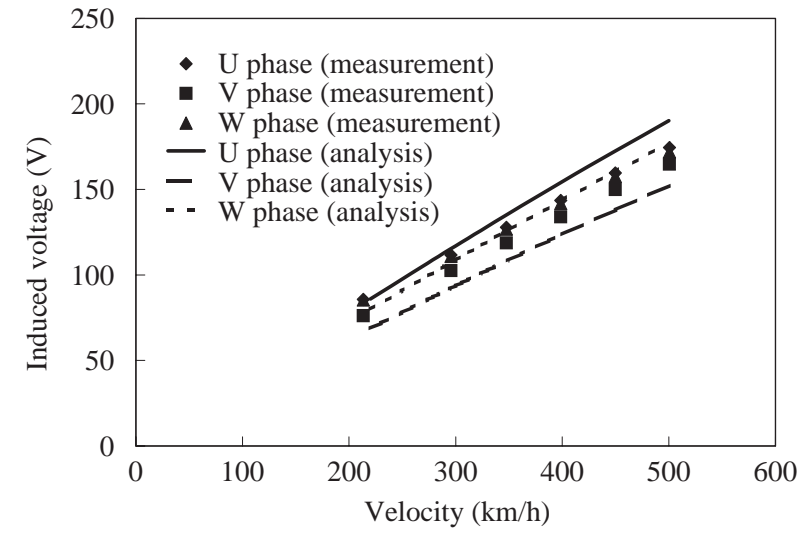

Fig. 8 Relationship between velocity and induced voltage

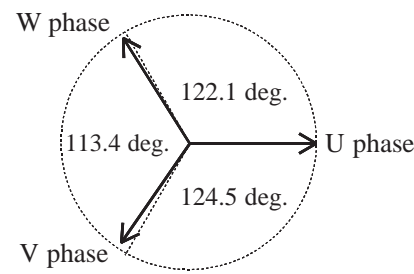

(a) Forward running

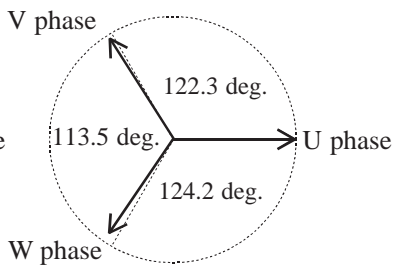

(b) Reverse running
Fig. 9 Vector diagram of induced voltage

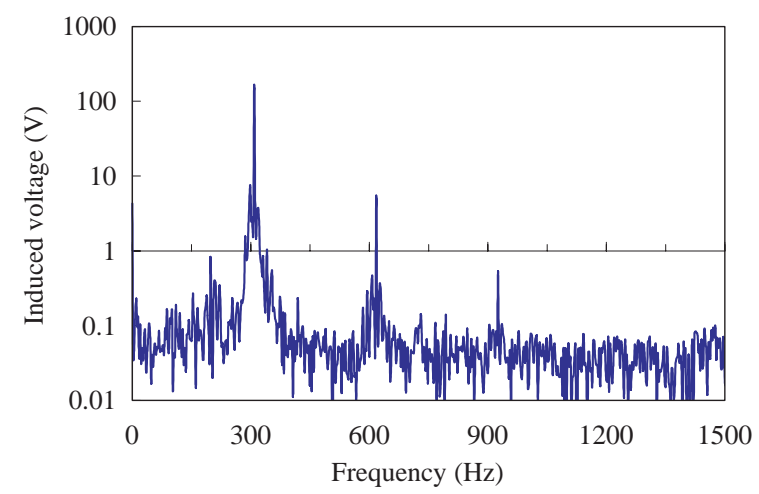

Fig. 10 Harmonics spectrum of induced voltage

$4 \%$ ). Phase unbalance was about $123 \pm 1 \mathrm{deg}$ and both measured and calculated values coincided well. Induced voltages are given as vectors in Fig. 9. We can confirm that it was nearly symmetric 3 -phase voltage.

As the generator coils in zero-phase current-type linear generator equipment have the irregular arrangement shown in Fig. 2, we were anxious about the harmful effects which this may generate. We show the results of Fourier analysis to induced voltage in Fig. 10. As shown in Fig. 10, the 2nd and 3rd harmonics are rather high but the ratio of inclusion is within a maximum of $5 \%$ and it was thus confirmed that there would be no problems.

\subsubsection{Power collection ability}

The overall performance features of the equipment in a test carried out to confirm power collection ability are shown in Fig. 11. For some time from the start, the vehicle runs in an electrically neutral position and not enough induced voltage is obtained, but after transitioning to levitation mode, a high induced voltage is generated. We set the starting velocity for power col- 


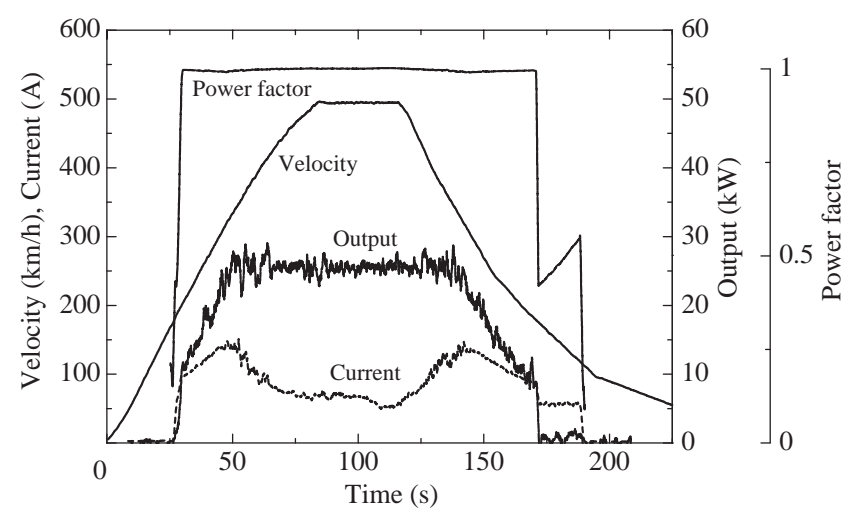

Fig. 11 Operation of linear generator

lection at $200 \mathrm{~km} / \mathrm{h}$ and Control for power factor to be maintained at 1 is also started at same speed. As velocity increases so does the induced voltage, but after the vehicle attains a speed of $300 \mathrm{~km} / \mathrm{h}$ and an objective power collection value of $25 \mathrm{~kW}$, the power collection current is reduced in order to maintain constant power. Collected power is maintained at a constant value even if aerodynamic lift force and transitioning to or from a curved section act as a disturbance on the power collection circuit. As velocity decreases, the power collection mode finishes at $200 \mathrm{~km} / \mathrm{h}$. During the test period, no unusual vibration or heat on the generator coils and SCM was detected and the efficacy of the design and installation was confirmed.

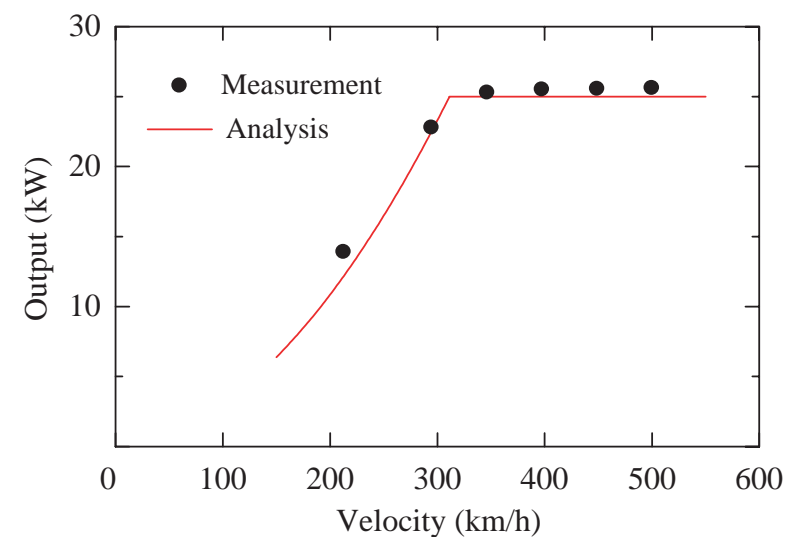

Fig. 12 Relationship between output and velocity (full payload)

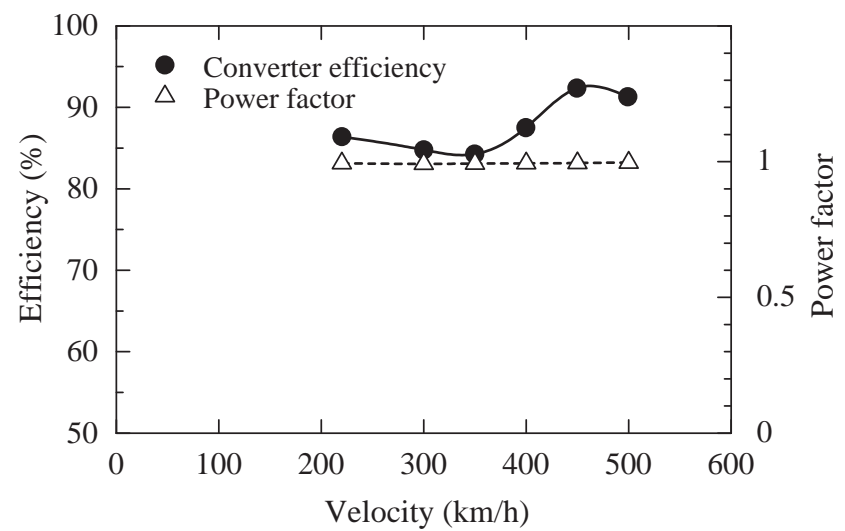

Fig. 13 Relationship between efficiency, power factor and velocity
The power collection characteristics with a full payload are shown in Fig. 12. We can confirm that the power collection target value of $25 \mathrm{~kW}$ was attained at a little over $300 \mathrm{~km} / \mathrm{h}$. Calculated power differed from that measured at low speed but generally coincided well.

Figure 13 shows converter efficiency and the power factor of the power collection circuit as a function of velocity. Converter efficiency drops to $85 \%$ at about $350 \mathrm{~km} /$ $\mathrm{h}$, the minimum efficiency value, when the current of the power collection circuit peaks. On the other hand, it reaches over $90 \%$ at more than $450 \mathrm{~km} / \mathrm{h}$. With regard to the power factor, it has been confirmed that more than 0.99 is attained at any velocity.

\subsubsection{Vibration control}

With regard to vibration control using zero-phase current control, we verified the response characteristics of the PI control system in a test run. The gain-frequency and phase-frequency characteristics are shown in Fig. 14. From these figures, it can be ascertained that the characteristic gain is about $100 \%$ until $20 \mathrm{~Hz}$, phase characteristics have about $1 \mathrm{deg} . / \mathrm{Hz}$ delay for increase of frequency, and we confirmed that zero-phase current control is responsive to control bogie vibration (primary suspension resonance frequency is about $4 \mathrm{~Hz} \sim 6 \mathrm{~Hz}$.) in the full-scale vehicle system. Several waveforms in the case of simultaneous power collection and vibration control are shown in Fig. 15, where the maximum zero-phase current was set at $100 \mathrm{~A}$. Not only did it display the good response characteristics of zero-phase current but also confirmed its ability to maintain stably a collected power setting $(25 \mathrm{~kW})$. We provide an example of the attenuation effect of bogie vibration in Fig. 16, in which the vertical axis (acceleration) is normalized by the maximum normal acceleration spectrum (without vibration control). It was confirmed that vibration in the $4 \mathrm{~Hz} \sim 6 \mathrm{~Hz}$ range decreases when vibration control is used. The above confirms that this vibration control method has a great effect on the EDS Maglev's primary suspension resonance frequency and that bogie vibration can be decreased to about $1 / 5$ in this frequency range.
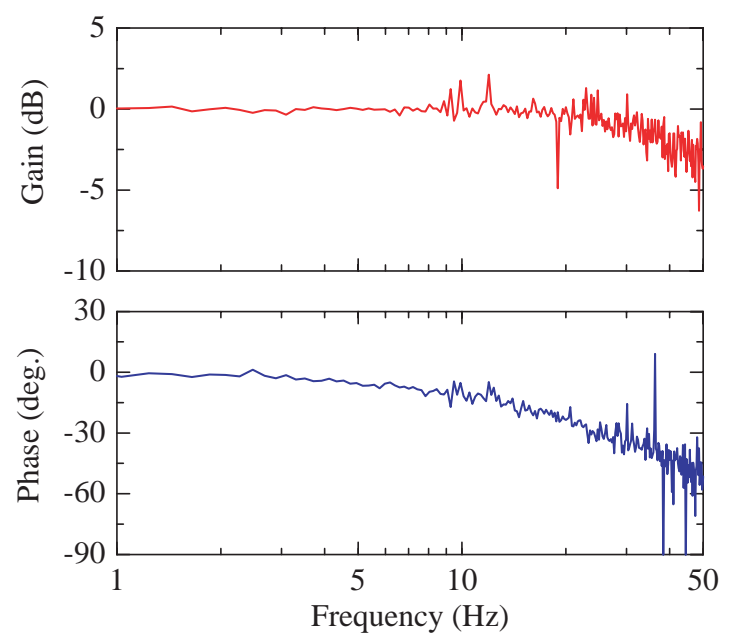

Fig. 14 Response of zero-phase current control 


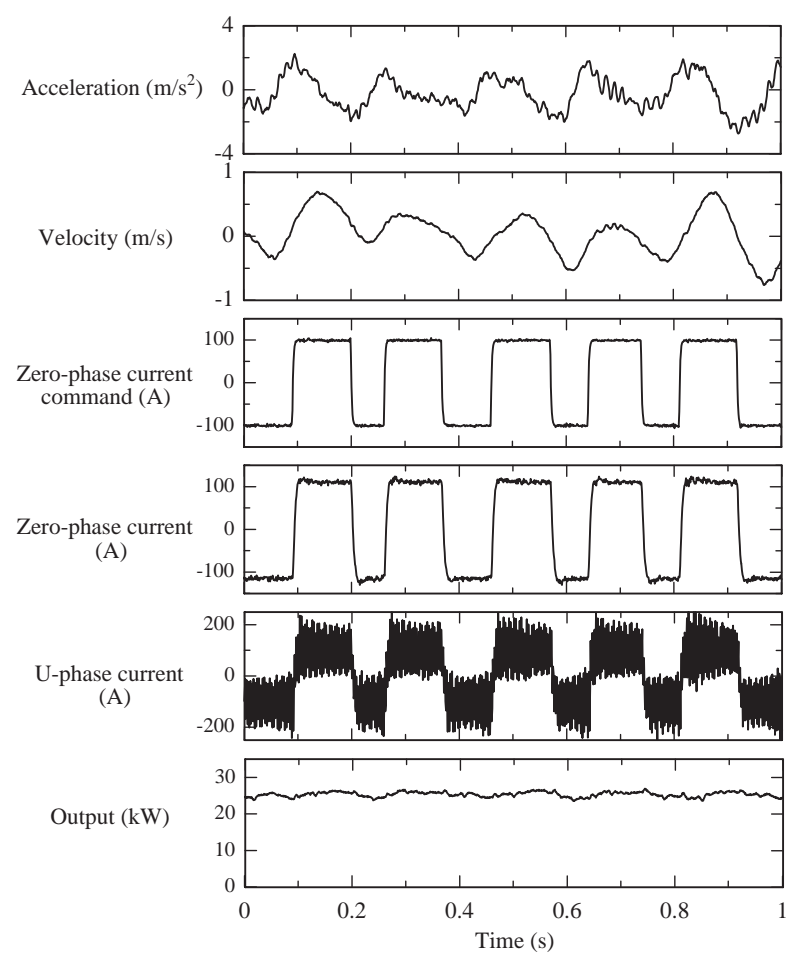

Fig. 15 Vibration control waveforms

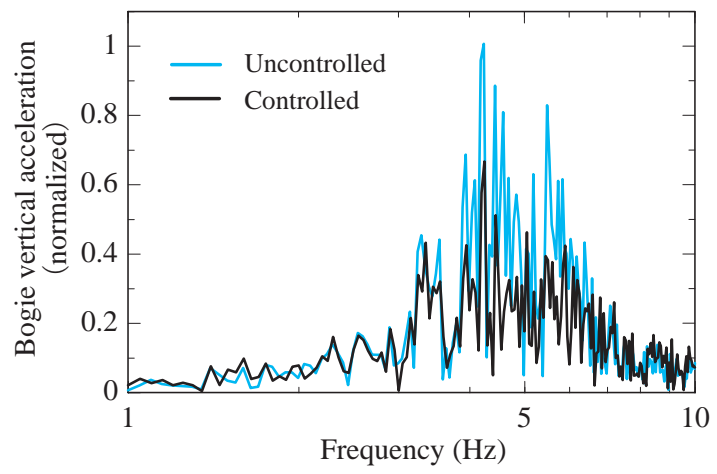

Fig. 16 Effect of vibration control

\section{Conclusion}

We developed a zero-phase current-type linear generator system combined with power collection and magnetic damping generation functions as one of the prominent candidates for an onboard power supply system on the superconducting Maglev system. To verify the system's applicability, we manufactured onboard test equipment and tested it on real test run. We obtained the following conclusive results.

(1) The absolute value of the measured induced voltage coincided with that calculated.

(2) With respect to induced voltage unbalance and harmonics, the amplitude unbalance, phase unbalance and harmonics ratio were all within $5 \%$ and no problems were encountered.

(3) In the system with real induced voltage and onboard load, the converter functioned well concerning power factor 1 control (more than 0.99) and the zero-phase current control responded well.

(4) With a full payload, the collected power target of $25 \mathrm{~kW}$ was achieved at just over $300 \mathrm{~km} / \mathrm{h}$.

(5) We were able to obtain stable collected power values with this system even when power collection and vibration control functions were used simultaneously.

(6) By using the vibration control function, bogie vertical vibration decreased to about $1 / 5$. There was a large damping effect near the primary suspension resonance frequency (magnetic levitation system).

The adaptability of the zero-phase current type linear generator system as an onboard power supply system and the usefulness of the primary suspension acting as damping control equipment were verified.

This work was financially supported in part by the Japanese Ministry of Land, Infrastructure and Transport.

\section{Acknowledgements}

The authors would like to express their sincere gratitude to Hitachi Co. Ltd., Toyo Denki Corporation and Central Japan Railway Company for providing invaluable test support.

\section{References}

1) Higashi, Ohashi, Ohsaki Masada, "Magnetic Damping of EDS Maglev," Trans. IEE Japan, Vol. 117-D, No. 8, pp. 1015-1023 (1997-8) (in Japanese).

2) Murai, T., Hasegawa, H. and Fujiwara, S.: "Improvement of Inductive Power Collection in Null-Flux EDS Maglev," Trans. IEE Japan, Vol. 117-D, No. 1, pp. 8190 (1997-1) (in Japanese).

3) Fujiwara, S., Murai, T. and Hasegawa, H.: "Magnetic Damping Method of EDS System Using Power Collection Coil," Trans. IEE Japan, Vol. 119-D, No. 2, pp. 254-259 (1999-2) (in Japanese).

4) Murai, T., Hasegawa, H., Yamamoto, T. and Fujiwara, S.: "Active Magnetic Damper Using Linear Generator," Trans. IEE Japan, Vol. 119-D, No. 11, pp. 13711376 (1999-11) (in Japanese).

5) Tanaka, M., Murai, T., Yamamoto, T., Hasegawa, H., Kashiwagi T. and Sakamoto, Y.: "Development of Linear Generator Coils Controlling Zero-Phase Current for a Superconducting Maglev," IEEJ Technical Meetings on Linear Drives, LD-04-29 (2004-1) (in Japanese).

6) Hasegawa, H., Murai, T. and Yamamoto, T.: "Running Tests of Combined SC Type Linear Generator," Trans. IEE Japan, Vol. 123-D, No. 2, pp. 156-163 (2003-2) (in Japanese).

7) Kashiwagi, T., Murai, T. and Yamamoto, T.: "OutputPhase Control of Converter for Inductive Power Collection System of EDS Maglev," Trans. IEE Japan, Vol. 124-D, No. 10, pp. 1029-1035 (2004-10) (in Japanese).

8) Hasegawa, H., Murai, T., Yamamoto, T. and Watanabe, E.: "Analysis of PWM Converter for Linear Generator Controlling on Zero-Phase Current", IEEJ Technical Meetings on Linear Drives, LD-02-118 (200212) (in Japanese) 